\title{
An attempt to assess eidetic imagery objectively*
}

\author{
KENT GUMMERMAN, CYNTHIA R. GRAY, and J. M. WILSON \\ University of Texas, Austin, Tex. 78712
}

The incidence of persons possessing eidetic imagery was determined for normal adults, normal school children, familial retardates, and brain-injured retardates (total $\mathrm{N}=270$ ). Three methods of evaluation were used for all Ss: (1) the "standard" method, in which the $S$ describes a complex scene after viewing it for $30 \mathrm{sec},(2)$ a task which requires superimposing the eidetic image of one stimulus upon a second stimulus, thus producing an unexpected third pattern; and (3) the Stromeyer and Psotka task of binocularly fusing two Julesz patterns, one of which is an eidetic image. The latter two methods were considered to be more objective than the first and less likely to incorrectly classify a person as an eidetiker. According to the first method, eidetikers were found only among the familial retardates (2 of $19 \mathrm{Ss}$ ); by the other two methods, none of the Ss possessed eidetic ability.

The eidetic image-a vivid, long-lasting, externally located visual image-has intrigued psychologists for many decades. In many early studies, the methods used to identify eidetikers were variations of the procedure described by Jaensch (1930) and Klüver (1928). The $S$, usually a child, fixates a colored square placed on a gray easel. After several seconds, the square is removed and the $S$ is asked to describe what he "still sees" (the afterimage). This preliminary procedure is intended to familiarize the $S$ with the experience of seeing images in the absence of stimuli and to encourage him to report any such experiences. After several such reports, the $S$ views a detailed scene on the easel but, in order to eliminate coherent afterimages, is asked to move his eyes about the picture. After the picture is removed, the $S$ is again requested to report what he "sees" while keeping his eyes on the blank easel. Though this procedure was fairly standard in eidetic research, investigators did not always agree upon the criteria for determining whether a $S$ had eidetic ability or not. For example, some insisted that accuracy of report was the determining feature, while others felt that image duration was critical (Teasdale, 1934). In more recent work, Haber \& Haber (1964) standardized the testing method and also established the following set of

* This research was supported in part by the National Science Foundation's University Science Development Program. Grant GU-1598. We are grateful to the Austin Independent School District and to the principal and staff of Summitt Elementary School for allowing us to test the elementary school children, and to the the elementary school children, and to the
Austin State School for their cooperation and assistance in testing the retarded children. criteria: (1) an image must be reported, (2) it must be colored positively, (3) it must be localized on the easel (rather than in the head), (4) the S must use the present tense to describe the image, and (5) eye movements made during the report must correspond to the part of the picture being described. Two secondary criteria are that the image last longer than $40 \mathrm{sec}$ and that the report be reasonably accurate.

By these standards, the incidence of eidetic ability among normal American elementary school children has been reported to be about 8\% (Haber \& Haber, 1964). According to Siipola \& Hayden (1965), the rate increases to $50 \%$ for children with brain injury, though Richardson \& Cant (1970) have presented contradictory data. There appears to be no other biological or functional variable to which eidetic imagery is related (Haber, 1969), though some investigators find high incidence of eidetic ability among tribes of primitive people (e.g., Doob, 1966).

Critics of research in eidetic imagery long ago proposed that the positive cases might be caused by artifacts in the testing procedure (Allport, 1928; see also Traxel, 1962). The Ss' reports of eidetic images may be made in response to what they think the $\mathrm{E}$ wants to hear or to the vagueness of the phrase "what you still see": one might report having an eidetic image when he is in fact experiencing a memory image. To answer this criticism, the testing procedure may be supplemented by tasks which unequivocally require the use of vivid, detailed images. The Habers have invested considerable energy in trying to devise such tests (Haber, 1969; Leask, Haber, \& Haber, 1969), but have found none with which eidetic children are reliably successful.
However, Stromeyer \& Psotka (1970) describe one adult $S$ who "saw" a stereoscopic picture that must have been the result of strong eidetic imagery. This $S$ viewed the left-eye and right-eye components of Julesz patterns (Julesz, 1964) sequentially rather than simultaneously. The interval separating the two viewings was as long as $2-24 \mathrm{~h}$, but the $\mathrm{S}$ could still identify the figure, which, for noneidetikers, appears only when the two eyes view the patterns simultaneously.

In the present study, Ss were tested for eidetic ability by (1) the standard procedure (Haber \& Haber, 1964), (2) the Stromeyer \& Psotka (1970) procedure, and (3) a superimposition task which resembles that of Stromeyer and Psotka but does not depend upon the S's ability to achieve binocular fusion. We expected that the first procedure might incorrectly classify as eidetic those Ss who were simply responding to the demands implicit in the procedure. Such Ss were expected to be incapable of performing either of the two more objective tasks. On the other hand, Ss with strong true eidetic ability were expected to succeed on either one or both of the objective tasks, as well as on the standard task.

\section{SUBJECTS}

A total of 270 Ss participated in all three testing procedures: 86 adults from introductory psychology courses at the University of Texas; 144 elementary school children, Grades 1-6; 16 brain-injured children (mean $\mathrm{IQ}=59.9, \mathrm{SD}=8.1$; mean $\mathrm{CA}=$ 12.8 years, $S D=1.2$; , and 19 familial retardates $($ mean $\mathrm{IQ}=59.6, \mathrm{SD}=7.9$; mean $\mathrm{CA}=12.9$ years, $\mathrm{SD}=1.2){ }^{1}$ In addition to these Ss, 318 introductory psychology students were screened for visual imagery by means of an imagery questionnaire. ${ }^{2}$ of these 318,31 were asked to return for further testing; 5 did return and were run through the entire procedure. Of these $5 \mathrm{Ss}, 4$ performed no differently than the 86 unscreened adults; these 90 adults will be treated as a single group. The fifth $\mathrm{S}$, however, was markedly different and will be considered separately. ${ }^{3}$

\section{APPARATUS AND STIMULI}

Four squares of colored paper, each 4 in. on a side and mounted on gray posterboard, were used in the standard afterimage task. The colors were red, blue, black, and yellow.

The stimuli for the picture description task measured about $10 \mathrm{x}$ 13 in. Two pictures were black silhouettes on gray backgrounds, and two were in full color. Content of the pictures was chosen for its appeal to children. One silhouette showed a girl investigating a box of toys; the other showed two boys playing ball. One 


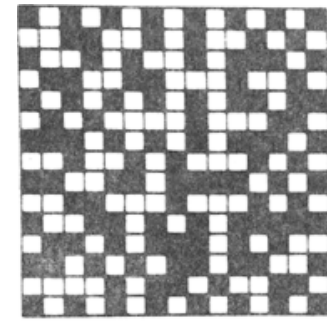

PATTERN A

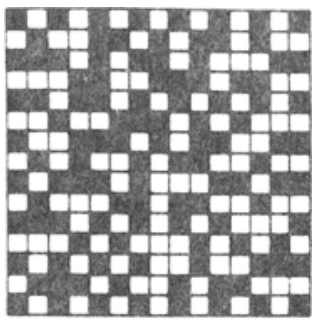

PATTERN 8

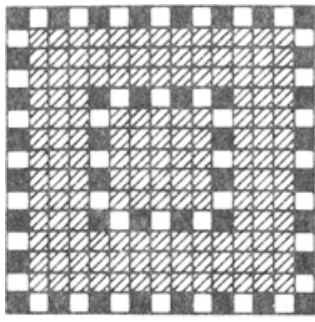

COMPOSITE

Fig. 1. Representation of one of the four stimulus pairs used in the checkerboard superimposition task. The $S$ viewed Patterns $A$ and $B$ sequentially. When $A$ and $B$ are superimposed either artificially (as by placing one on top of the other and holding them in front of a strong light) or eidetically (by retaining an image of $A$ and "projecting" it onto B), the composite figure may be seen. Patterns $A$ and $B$ both had alternating black-white borders to simplify the task of aligning them properly when superimposed.

colored picture displayed the same scene as the first silhouette; the other was a very detailed scene of a teacher reading to children in a classroom.

Stimuli for the checkerboard superimposition task (see Fig. 1) consisted of four pairs of $6 \times 6$ in. matrices ( 15 cells on a side). Half the cells in each matrix were blackened in patterns that appeared to be random. In fact, the blackening was done so that superimposing the members of each pair would result in the appearance of a distinct pattern (a square, a cross, a triangle, or "stair-steps") that was not at all predictable from the matrix patterns.

Stimuli for these first three tasks were presented on an easel (a stiff sheet of gray posterboard) that rested upon a table at an angle suitable for comfortable viewing. The viewing distance varied from about 12 to 20 in.

Materials for the final task were three pairs of Julesz dot patterns, which, when fused binocularly, would result in views of a square, a rectangle, or a pair of rectangles. The patterns were presented in a Keystone Televiewer stereoscope, which was mounted in a $24 \times 18$ in. frame of black wood to prevent the Ss from viewing the materials being inserted. Illumination was provided by a $15-\mathrm{W}$ bulb placed 12 in. from the patterns and by normal room illumination. Two small pieces of wood, attached to the frame, could be moved to occlude either eye.

Before the testing began, the children were told that sometimes people could see things that were not really there and asked whether they had ever had such an experience. The $E$ mentioned several cases of afterimages that the child might have experienced. The Ss were then assured that it was perfectly all right if they did see something that "wasn't really there" during the course of the testing. Each $\mathbf{S}$ was first presented the four color squares, one at a time, for $15 \mathrm{sec}$ each. The $\mathbf{S}$ was instructed to look at the center of the color square, without moving his eyes, and to remain looking at the easel even after the square was removed, at which time he was to describe what he saw on the easel. The $S$ was reminded at appropriate intervals to report when the image was gone.

The $S$ was next presented the four scenes, one at a time, for $30 \mathrm{sec}$ each. The $\mathrm{S}$ was instructed to move his eyes freely about all parts of the picture, but to remain looking at the easel after the picture was removed. He was then to report what he saw. If the $S$ said he saw nothing, the $E$ asked him to describe what he remembered about the picture. When the S's voluntary report stopped, the $E$ prompted him by asking about details of the picture. Again, the $E$ reminded the $S$ at appropriate intervals to mention when the picture was gone. During the description, the $E$ noted the presence or absence of images, image duration, eye movements, and the tense used by the $S$. The $E$ had a checklist of items comprising each stimulus; as items were named, they were marked on the list.

Next, the checkerboard pairs were presented. The first pattern was viewed for $30 \mathrm{sec}$. It was then removed, and the second pattern was immediately placed in the same position for $30 \mathrm{sec}$. The $\mathrm{S}$ was instructed to move his eyes freely about the patterns and to report what he saw when the second pattern was presented.

Finally, the $S$ viewed the first pair of Julesz patterns simultaneously, in order to ascertain whether fusion could be achieved under normal conditions. The other two pairs were then presented. The first pattern of each pair was shown for 30 sec to one eye; it was then occluded, and the second pattern was exposed for $30 \mathrm{sec}$ to the other eye. In each case, the $\mathrm{S}$ was asked to report what he saw when viewing the second pattern.

\section{RESULTS}

Standard Task

Based on Haber \& Haber's (1964) five criteria, only 2 of the $270 \mathrm{Ss}$ tested had eidetic ability. Contrary to the expectations aroused by Siipola \& Hayden's (1965) study, these Ss were both from the group of familial retardates. These two children were the only Ss to consistently report images of any kind after the pictures were removed, they reported images for all four pictures. Only one other S reported any image at all; this was one of the brain-injured children, who reported a 2 -sec positively colored image to one of the silhouettes. He showed no other signs of eidetic ability.

The two eidetikers, " $H$ " and " $L$ :" were rather different in certain aspects of their behavior. $\mathrm{H}$ (male, $\mathrm{CA}=15$, $\mathrm{IQ}=61$ ) reported unusual afterimages in response to the colored squares-from two to five different colors appearing in sequence. Such a "flight of colors" was rarely reported by other Ss. When reporting the afterimages and the images from the pictures, $H$ behaved curiously. He placed his face 2 to $4 \mathrm{in}$. from the easel and expressed great fascination with what he described. His eyes tended to jerk slightly at times, as though the image were moving of its own volition on the easel. At the $E$ 's suggestion, he could move the image off the edge of the easel, which resulted in its disappearance. At one point, he said that the image was "little." This remark, along with the movement of the image, may lead one to suspect that $\mathrm{H}$ 's images were, in fact, afterimages. However, since he reported positive coloring, moved his eyes over the pictures during the inspection periods, and scanned the easel while making his reports, coherent afterimages probably did not occur. H's four picture images lasted from $30 \mathrm{sec}$ to $4 \mathrm{~min}$ (mean $=2 \mathrm{~min}$ $30 \mathrm{sec}$ ). All his reports were made confidently and in present tense. The other eidetiker, $\mathrm{L}$ (male, $\mathrm{CA}=12, \mathrm{IQ}$ $=67$ ), reported positive afterimages of the colored squares. His images of the pictures, which lasted from $1 \mathrm{~min}$ $45 \mathrm{sec}$ to $3 \mathrm{~min}($ mean $=2 \mathrm{~min} 8 \mathrm{sec})$, did not seem to move about on the easel, and he stayed a normal distance from the easel.

As expected, the accuracy of the picture descriptions (see Table 1) was highest for the adult Ss, intermediate for the normal children, and lowest for the retarded children. H's recall score was $18.3 \%$, very much like the others 
in his group. L's score was $30.8 \%$, the best of his group, though not unusual when compared to the scores of normal children. The score of the $\mathrm{S}$ described in Gummerman \& Gray (1971) was $83.3 \%, 4.1 \mathrm{SD}$ above the mean of the adult group. Despite her unusual accuracy, this $\mathbf{S}$ was not eidetic.

\section{Superimposition Tasks}

No $S$ in any group-including the two eidetikers was able to perform either of these tasks. Furthermore, very few of the children (and none of the retardates) were able to achieve fusion with simultaneously presented Julesz patterns. Consequently, it is not so surprising that the children could not do the task when the patterns were presented sequentially.

\section{DISCUSSION}

The proportions of persons that our standard task classified as eidetic are, at first glance, surprisingly low (for all but the familial retardates). Close inspection of the literature reveals, however, that such discrepancies are in fact quite common. Among the older studies, for example, rates among normal children vary from $0 \%$ to $100 \%$ (Klüver, 1931, p. 656); and, more recently, the $8 \%$ figure from Haber \& Haber (1964) may be contrasted with Traxel's (1962) failure to find any true eidetikers in his sample of 174 normal children. ${ }^{4}$ In addition, the frequencies found for retarded children are inconsistent from study to study (cf. Siipola \& Hayden, 1965, and Richardson \& Cant, 1970).

The reasons for these frequency differences using the standard method are not at all clear. One possibility-that the various studies have tapped strikingly different populations of Ss-is not appealing, for any factor that might have produced the differences has eluded identification for many years and must be extremely subtle and resistant to analysis. Another potential explanation is that some noneidetic Ss report seeing images in order to behave in a manner expected to produce approval or attention. While we rriously doubt that any $E$ in recent years would communicate the goals of his study to the $S$ in any overt manner, great care must be taken to prevent school children from learning about the task from classmates who have already served as Ss. Moreover, as Traxel (1962) has noted, the very structure of the task (e.g., eliciting afterimage reports and then asking if the $S$ sees anything on the blank easel where a picture had just been displayed) should be expected to elicit reports of images from persons who are merely very suggestible or very anxious to please the E. Finally, one need not even suppose that Ss actually

Table 1

Percent Items Recalled in Standard Task, Pooled Over All Four Pictures

\begin{tabular}{|c|c|c|c|c|}
\hline Group & $\mathbf{N}$ & Mean & Range & SD \\
\hline Adults* & 90 & 46.2 & $19.2-65.0$ & 9.1 \\
\hline $\begin{array}{r}\text { Normal Childr } \\
\text { Grade } 1 \\
2 \\
3 \\
4 \\
5 \\
6\end{array}$ & $\begin{array}{l}19 \\
26 \\
27 \\
22 \\
24 \\
26\end{array}$ & $\begin{array}{l}20.9 \\
24.8 \\
25.5 \\
22.0 \\
31.3 \\
28.6\end{array}$ & $\begin{array}{l}10.0-32.5 \\
15.0-38.3 \\
15.0-45.8 \\
10.8-33.3 \\
20.0-37.5 \\
15.0-40.8\end{array}$ & $\begin{array}{l}5.7 \\
6.1 \\
6.3 \\
6.6 \\
4.3 \\
6.7\end{array}$ \\
\hline $\begin{array}{l}\text { Brain-Injured } \\
\text { Retardates }\end{array}$ & 16 & 15.3 & $3.3-27.5$ & 5.6 \\
\hline $\begin{array}{c}\text { Familial } \\
\text { Retardates } †\end{array}$ & 17 & 16.1 & $9.2-26.7$ & 4.3 \\
\hline
\end{tabular}

*The noneidetic $S$ described by Gummerman and Gray (1971) is not included here. tThe two eidetic $S s$ are not included here.

"fake" their reports of images. Visual memory is an ability that most normal persons possess, to varying degrees; Ss with moderate or strong (but not eidetic) visual memory are quite likely to confuse this memory with eidetic images. Unfortunately, these potential sources of error are very difficult to control, and their effects (if any) upon scores in the standard task cannot be easily assessed.

of particular interest is our finding that the two children classified as eidetic by the standard method were unable to perform either of the more objective tasks. This result may be accounted for in two ways. First, the children may not be eidetikers at all; they merely may have acted like aidetikers in the standard task because of its demand characteristics or because they had difficulty distinguishing between visual memory images and eidetic images. Second, they may have true eidetic ability and yet lack the extremely detailed images required by the objective tasks (images such as Stromeyer and Psotka's S had). Leask, Haber, \& Haber (1969), in fact, believe that eidetic images can on occasion be fragmentary and incomplete. This explanation seems feasible for the task involving Julesz patterns, especially in view of the retarded children's difficulty in obtaining stereopsis. The other superimposition task, while considerably less demanding, could also be too difficult for any but the most proficient eidetiker to perform.

The intent of this study was to determine the proportion of eidetikers-as defined by the standard task-who have images sufficiently detailed, vivid, and accurate to enable them to perform the superimposition tasks. Since only two eidetikers were discovered, however, we do not feel justified at this time in placing much confidence in the power of these superimpusition tasks to discriminate among degrees of image "strength."
Rather, the principal effect of the investigation has been to underscore the evanescent, perplexing character of the eidetic image.

\section{REFERENCES}

ALLPORT, G. W. The eidetic image and the after-image. American Journal of Psychology, 1928, 40, 418-425.

DOOB, L. W. Eidetic imagery: A cross-cultural will-o'-the-wisp? Journal of Psychology, 1966, 63, 13-34.

GUMMERMAN, K., \& GRAY, C. R. Recall of visually presented material: An unwonted case and a bibliography for eidetic imagery. Psychonomic Monograph Supplements, $1971,4(10$, Whole No, 58).

HABER, R. N. Eidetic images. Scientific American, 1969, 220, 36-44.

HABER, R. N., \& HABER, R. B. Eidetic imagery: I. Frequency. Perceptual \& Motor Skills, $1964,19,131.138$.

JAENSCH, E. R. Eidetic imagery. London Kegan Paul, Trench, Trubner (New York Harcourt Brace), 1930.

JULESZ, B. Binocular depth perception without familiarity cues. Science, 1964. 145, 356-362.

KLÜVER, $H$. An experimental study of the eidetic type. Genetic Psychology Monographs, 1926, 1, 71-230.

KLUVER, $H$. Studies on the eidetic type and on eidetic imagery. Psychological Bulletin, 1928, 25, 69-104

KLÜVER, $H$. The eidetic child. In $C$. Murchison (Ed.), A handbook of child psychology. (1st ed.) Worcester: Clark University Press, 1931. Pp. 643-668.

LEASK, J., HABER, R. N., \& HABER, R. B. Eidetic imagery in children: II. Longitudinal and experimental results. Psychonomic Monograph Supplements, $1969,3(3$, Whole No. 35)

RICHARDSON, A., \& CANT, R. Eidetic imagery and brain damage. Australian Journal of Psychology, 1970, 22, 47-54.

SIIPOLA, E. M., \& HAYDEN, S. D. Exploring eidetic imagery among the retarded. Perceptual \& Motor Skills, $1965,21,275.286$.

STROMEYER, C. F., III, \& PSOTKA, J The detailed texture of eidetic images. Nature, 1970, 225, 346-349.

TEASDALE, H. A quantitative study of eidetic imagery. British Journal of Educational Psychology, 1934, 4, 56-74.

TRAXEL, W. Kritische Untersuchungen zur Eidetik. Archiv für die gesamte Psychologie, 1962, 114, 260-336. NOTES

1. Classification was based on the institution's diagnoses. We considered 
several types of problems to be "brain injury," including structural defects due to prematurity, structural defects of unknown cause, mechanical injury at birth, prenata or postnatal cerebral infection, anoxia, and postnatal injury. Children were considered to be familial retardates if they suffered functional deficits caused by familial, cultural, or unknown factors. Psychotic children and children with major personality disorders were excluded from the sample, as were those suffering from mongolism and hydrocephaly.

2. This questionnaire was adapted from Klùver (1926, pp, 92-93). One of his items asked whether the respondent knew any eidetikers; this item was not scored. Of the eidetikers; this item was not scored. Of the remaining 13 questions, positive answers to evidence of strong imagery to test the $S$ further.

3. This $S$ has been described by Gummerman \& Gray (1971). The picture descriptions reproduced in that report were made after the' $S$ had participated in the present experiment.

4. Three of Traxel's Ss reported seeing brief visual images, but he felt that they were in fact positive afterimages or memory images. 